\title{
Characteristics of turbulence driven atmospheric blur over coastal water
}

\author{
Arie N. de Jong ${ }^{\mathrm{a}}$, Piet B.W. Schwering ${ }^{\mathrm{a}}$, Koen W. Benoist ${ }^{\mathrm{a}}$ \\ Willem H. Gunter ${ }^{\mathrm{b}}$, George Vrahimis ${ }^{\mathrm{b}}$, Faith J. October ${ }^{\mathrm{b}}$ \\ ${ }^{a}$ TNO, PO Box 96864, The Hague, The Netherlands \\ ${ }^{\mathrm{b}}$ Institute for Maritime Technology (IMT), Simon's Town 7995, South Africa
}

\begin{abstract}
For users of Electro-Optical (EO) sensors at sea, knowledge on their resolution is of key operational importance for the prediction of the obtainable classification ranges. Small targets may be located at ranges of $20 \mathrm{~km}$ and more and the present day sensor pixel size may be as small as $10 \mu \mathrm{rad}$. In this type of scenarios, sensor resolution will be limited by blur, generated by atmospheric turbulence, easily being greater than $30 \mu \mathrm{rad}$ (at $20 \mathrm{~km}$ range). Predictions of the blur size are generally based upon the theory, developed by Fried [1]. In this theory, the turbulence strength is characterized by the structure parameter for the refractive index $\mathrm{C}_{\mathrm{n}}{ }^{2}$, of which data are assumed to be available from secondary instruments. The theory predicts the atmospheric Modulation Transfer Function (MTF), which can be incorporated into the total system MTF, used in range performance predictions, as described by Holst [2]. Validation of blur predictions by measurements is a complex effort due to the rapid variations of the blur with time and the problems associated with the simultaneous acquisition of proper $\mathrm{C}_{\mathrm{n}}^{2}$ data. During the FATMOSE trial, carried out over a range of $15.7 \mathrm{~km}$ in the False Bay near Simon's Town (South Africa) from November 2009 to October 2010, these data were collected in a large variety of atmospheric conditions [3]. In stead of the atmospheric MTF, the horizontal and vertical line spread function (LSF) was measured with a camera with $5 \mu$ rad resolution. Various methods for the determination of the LSF and the associated problems are discussed in the paper. The width of the LSF is via its Fourier transform directly related to the MTF. $\mathrm{C}_{\mathrm{n}}{ }^{2}$ data were collected with a standard BLS scintillometer over a nearby range. Additional $\mathrm{C}_{\mathrm{n}}{ }^{2}$ data were obtained via conversion of the scintillation data from the same camera and from a high speed transmissometer, collecting data over the same range. Comparisons between blur and Beam Wander predictions and measurements from the FATMOSE campaign are discussed in the paper as well as their impact on the range performance of present day sensors at sea.
\end{abstract}

KEYWORDS: atmospheric blur, turbulence, beam wander, scintillation, littoral water, marine boundary layer

\section{INTRODUCTION}

An important application of electro-optical systems is surveillance in coastal areas by using shore-based or ship-borne sensors. Common targets of interest are for example small boats with people on board. Requirements for the sensors include the ability of counting numbers of people and the detection of potential weapons at ranges up to $20 \mathrm{~km}$ and more. In this kind of application a modern sensor with an angular resolution of $10 \mu$ radian could give just enough resolution, if the atmospheric blur is neglected. Of course the atmospheric transmission should be sufficient in cases of long range target detection. As was shown in an earlier FATMOSE paper [4], the visibility in the False Bay area is greatly influenced by strong prevailing South Eastern winds, generating sea particles into the air. For the range of $15.7 \mathrm{~km}$ however, during most of the time (more than $90 \%$ for the whole year) the visibility was good enough to collect LSF data.

Most of the atmospheric blur measurements up to now, have been carried out in a land environment. At sea and in a coastal region, logistic problems hamper year-round experiments. As a consequence few data are available on $\mathrm{C}_{\mathrm{n}}{ }^{2}$ and the associated blur. It was shown [5], that during FATMOSE the mean year-round value of $\mathrm{C}_{\mathrm{n}}{ }^{2}$ for the False Bay is $10^{-15}$ $\mathrm{m}^{-2 / 3}$, which is a factor 10 lower than commonly measured in a land environment. Statistics of $\mathrm{C}_{\mathrm{n}}{ }^{2}$ for the FATMOSE trials area during the trials period are shown in Figure 1, together with other weather parameters, relevant for long range target detection and classification. These parameters, measured on the Roman Rock Lighthouse (RRL), located at $2 \mathrm{~km}$ from the shore characterize the trials site. Included in Figure 1 are the statistics of the transmission, measured with the multispectral transmissometer for the same spectral band as the camera, used for the LSF measurements. This camera,

Remote Sensing of Clouds and the Atmosphere XIX; and Optics in Atmospheric Propagation and Adaptive Systems XVII, edited by Adolfo Comerón, Evgueni I. Kassianov, Klaus Schäfer, Richard H. Picard, Karin Stein, John D. Gonglewski, Proc. of SPIE Vol. 9242, 92421H · @ 2014 SPIE · CCC code: 0277-786X/14/\$18 · doi: 10.1117/12.2066192 
consisted of a $200 \mathrm{~mm}(\mathrm{f} / 10$ ) Celestron telescope and a Marlin 640x480 camera with 10x10 $\mu \mathrm{m}$ pixels. The method for obtaining the blur data with this camera is described in a special section. In section 2, the prediction of blur and beam wander with the impact of $\mathrm{C}_{\mathrm{n}}{ }^{2}$ values is discussed for the "classical" and new method. In section 3 the retrieval of $\mathrm{C}_{\mathrm{n}}{ }^{2}$ values is presented. Section 4 concerns the method of data analysis, while in sections 5 and 6 data are presented and comparisons are made between prediction and measurement. In the section on conclusions, the impact of atmospheric blur on the range performance is illustrated. It is noted, that the strong winds in the False Bay area, provide considerably worse $\mathrm{C}_{\mathrm{n}}^{2}$ conditions than in calmer open ocean conditions, so it may be assumed, that blur (and visibility) conditions are generally better in open ocean conditions. Furthermore it was found, that the water temperature and thus the Air Sea Temperature Difference (ASTD) along the $15.7 \mathrm{~km}$ path, is generally not constant. This is caused by the mixing in the False Bay of cold water from the Benguela current and warm water from the Agulhas current.
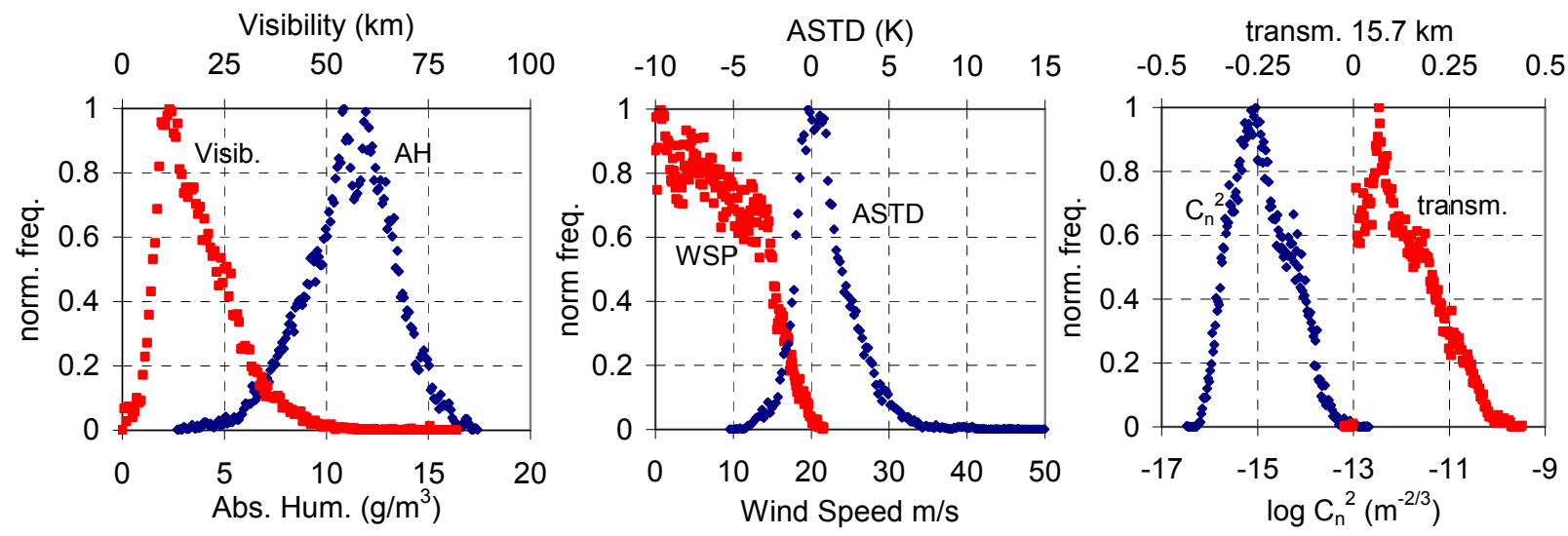

Figure 1. Year-round normalized frequencies of occurrence for the Visibility and Absolute Humidity (left), Wind Speed and ASTD (centre) and $\mathrm{C}_{\mathrm{n}}{ }^{2}$ (from BLS) and transmission along the $15.7 \mathrm{~km}$ path in the spectral band 0.7-1.0 $\mu \mathrm{m}$ (right)

The consequence is that extremely low $\mathrm{C}_{\mathrm{n}}^{2}$ values, according to the Monin-Obukhov theory predicted for small ASTD values, are rarely found [6]. Another remark concerns the minimum level of $\mathrm{C}_{\mathrm{n}}^{2}$, obtainable with the Scintec BLS900 scintillometer, was about $10^{-16} \mathrm{~m}^{-2 / 3}$. Lower values could however be determined from values of the Scintillation Index (SI), as measured with the Multi Spectral Radiometer Transmissometer (MSRT) and with the sensor, used for the LSF measurements. It is noted that due to the long range, corrections were made for the effect of pupil averaging on the SI for the sources and sensors, according to the guide lines from Andrews [8].

\section{PREDICTIONS OF BLUR AND BEAM WANDER}

The commonly used theory of turbulence, as introduced by Kolmogorov, describes the 3-D fluctuations of air speed and the resulting spatial fluctuations in air temperature and refractive index $n$ [9]. The spatial statistics of $\mathrm{n}$ are described by the structure function $\mathrm{D}_{\mathrm{n}}(\mathrm{r})=<\left\{\mathrm{n}\left(\mathbf{r}_{1}\right)-\mathrm{n}\left(\mathbf{r}_{1}+\mathbf{r}\right)\right\}^{2}>$ and the structure function parameter $\mathrm{C}_{\mathrm{n}}{ }^{2}$, defined by $\mathrm{D}_{\mathrm{n}}(\mathrm{r})=\mathrm{C}_{\mathrm{n}}{ }^{2} \mathrm{r}^{2 / 3}$, where $\mathbf{r}_{1}$ and $\mathbf{r}$ are vectors in space and $\mathbf{r}$ the magnitude of $\mathbf{r}$. According to the theory of Kolmogorov, the 3-dimensional spectrum $\Phi(\mathrm{K})$ of the turbulence fluctuations decreases with wave number $\mathrm{K}$ as: $\Phi(\mathrm{K})=0.033 \mathrm{C}_{\mathrm{n}}{ }^{2} \mathrm{~K}^{-11 / 3}$. The refractive index fluctuations along and transverse to an optical path, create disturbances to a wavefront, propagating through the atmosphere. Elements from such a disturbed wavefront may interfere in the focal plane after entering the pupil of an optical sensor. The total interference pattern is a combination of the atmospheric effect and the diffraction of the pupil. If only the atmospheric turbulence is taken into account, Fried [1] derives the formula for the atmospheric MTF:

$$
\operatorname{MTF}(f)=\exp \left[-3.44\left(\lambda f 10^{3} / r_{0}\right)^{5 / 3}\left\{1-b\left(\lambda f 10^{3} / D\right)^{1 / 3}\right\}\right] \quad \text { with } \quad r_{0}=2.1\left\{1.46(2 \pi / \lambda)^{2} C_{n}^{2} R\right\}^{-3 / 5}
$$

Here $\mathrm{D}$ and $\lambda$ represent the diameter respectively the centre wavelength of the optical sensor. $\mathrm{R}$ is the distance between source and sensor and $\mathrm{r}_{0}$ is the atmospheric coherence length, the maximum separation at which spatial coherence exists. Actually an alternative parameter $\rho_{0}$, the transverse coherence length, is frequently used, related to $r_{0}$ by: $r_{0}=2.1 \rho_{0}$. Two points on a wave front at a distance greater than $\rho_{0}$ will be uncorrelated. The constant $b$ in formula (1) is determined by 
the type of application, either long exposure (LE, $\tau>>5 \mathrm{~ms}$ ) or short exposure (SE, $\tau<<5 \mathrm{~ms}$ ) time. In the case of LE, $b=0$ is taken; for the case of SE, $b=1$ in the near field or $b=0.5$ in the far field. In our situation we did use collimated sources, creating plane waves with an infinitely wide Fresnel zone at the sensor pupil, so we take $b=0.5$. For the set up during FATMOSE, $\mathrm{R}=15.7 * 10^{3} \mathrm{~m}$, while the sensor parameters were: $\lambda=0.8^{*} 10^{-6} \mathrm{~m}$ and $\mathrm{D}=0.2 \mathrm{~m}$. The spatial frequency $\mathrm{f}$ is given in cycles $/ \mathrm{mrad}$. Taking the case of $\mathrm{C}_{\mathrm{n}}{ }^{2}=10^{-15} \mathrm{~m}^{-2 / 3}$, we obtain a value for $\mathrm{r}_{0}$ of $0.027 \mathrm{~m}$ and a predicted MTF curve as shown in Figure 2. It appears, that the MTF values are higher than a standard Gaussian for spatial frequencies above the $1 / \mathrm{e}$ point $(18.5 \mathrm{c} / \mathrm{mrad})$ of the curve. Figure 2 (right) also shows the Fourier transform of the MTF, being the
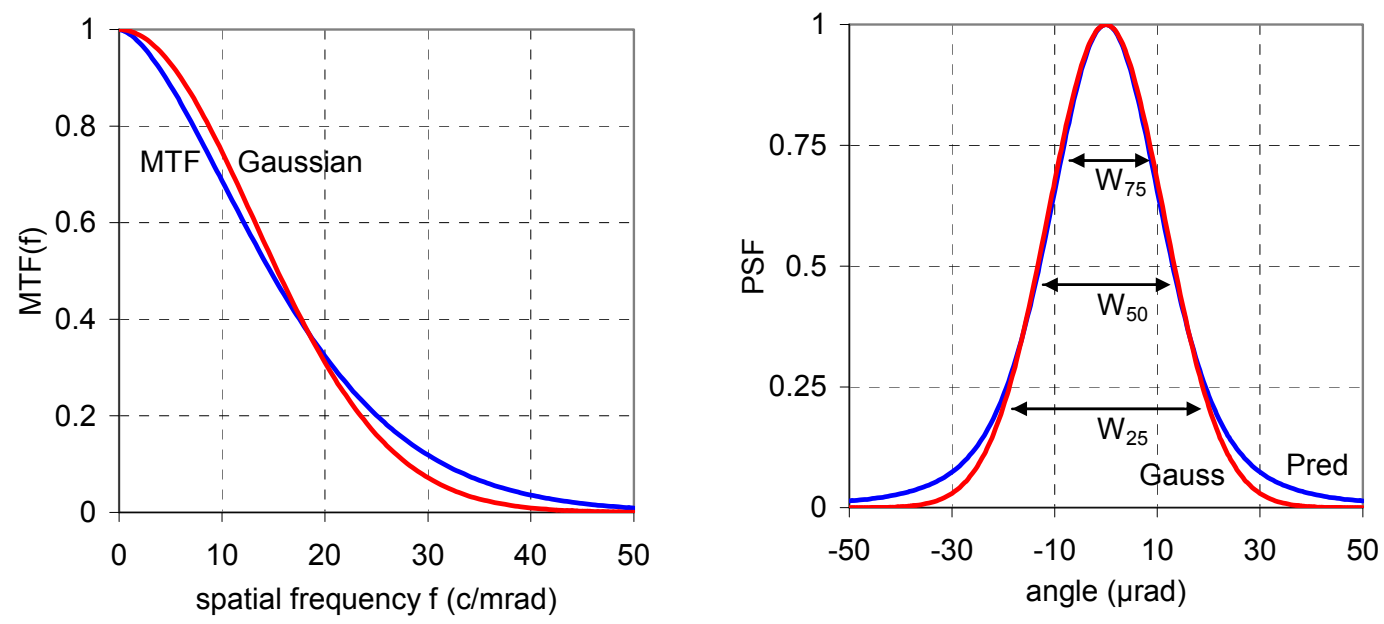

Figure 2. Predicted atmospheric MTF and the associated PSF, compared with "Gauss" fits for $\mathrm{C}_{\mathrm{n}}{ }^{2}=10^{-15} \mathrm{~m}^{-2 / 3}$

Point Spread Function (PSF) in comparison with a Gaussian curve, crossing at the 1/e point. It appears that both curves are very near above the 0.25 level. This makes the conversion to the LSF easier as the PSF and the LSF are identical for Gaussian type curves. The advantage of the LSF is related to its measurement from the Marlin images of the blur spots, which generally show considerable inhomogeneities. By taking the LSF, intensities are integrated in one direction, which gives a better signal to noise ratio. In Figure 2 three widths are shown: at $75 \%$ of the peak $\left(\mathrm{W}_{75}\right)$, at $50 \%\left(\mathrm{~W}_{50}\right)$ and at $25 \%\left(\mathrm{~W}_{25}\right)$, which correspond to the widths as measured during the image analysis (see section 4).
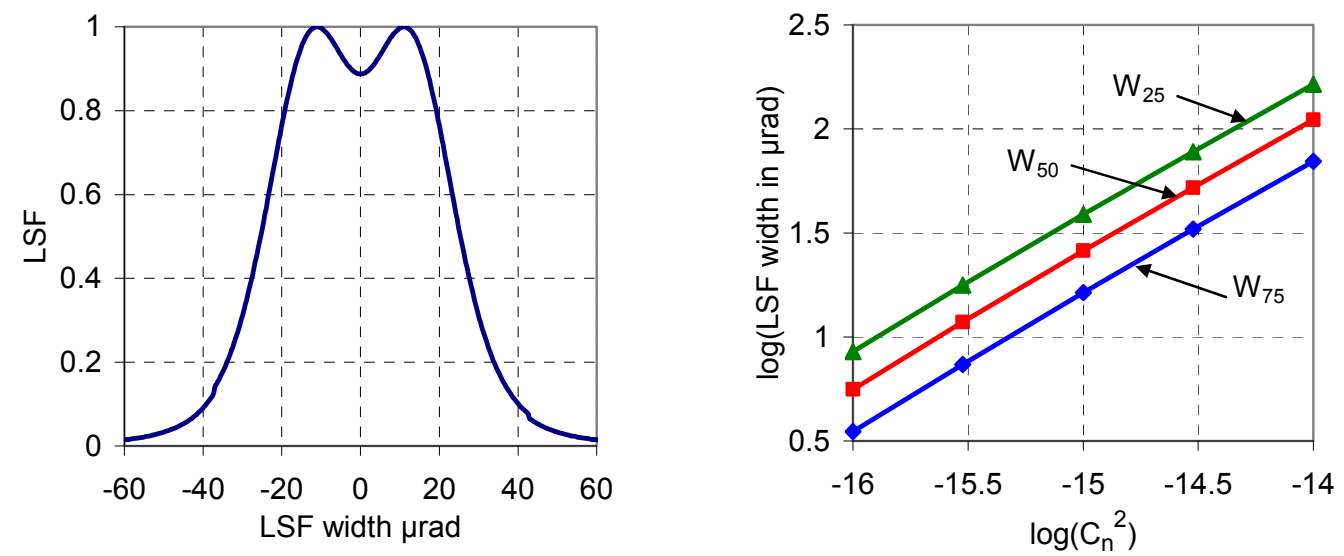

Figure 3. Simulation of two sources, separated by an angle of $\mathrm{W}_{50}$ (left) and relation between LSF widths $\mathrm{W}_{75}, \mathrm{~W}_{50}$ and $\mathrm{W}_{25}$ and $\mathrm{C}_{\mathrm{n}}^{2}$ for the situation during FATMOSE

In Figure 3 (left), the LSF's of two neighbouring sources at a distance of $\mathrm{W}_{50}$ are shown. The signal dip of about $11 \%$ in the middle of the signal peaks, is just enough to make the two sources discernable with modern processing systems. A similar criterion was used by Rayleigh to discriminate two sources in diffraction limited optical systems. In this paper we define $\mathrm{W}_{50}$ as the blur, where the measured blur has to be corrected for sensor blur (see section 4). 
In Figure 3 the relations between $\mathrm{W}_{75}, \mathrm{~W}_{50}$ and $\mathrm{W}_{25}$ and $\mathrm{C}_{\mathrm{n}}{ }^{2}$ are shown for $\mathrm{C}_{\mathrm{n}}{ }^{2}$ values between $10^{-16}$ and $10^{-14} \mathrm{~m}^{-2 / 3}$. The linear relationship between the parameters, makes it simple to predict the blur $\mathrm{W}_{50}$ for any value of $\mathrm{C}_{\mathrm{n}}{ }^{2}$. The equation of the regression line for $\mathrm{W}_{50}$ (in $\mu \mathrm{rad}$ ) is found to be:

$$
\log \left(\mathrm{W}_{50}\right)=0.6478^{*} \log \left(\mathrm{C}_{\mathrm{n}}^{2}\right)+11.122 \quad \text { from which follows: } \quad \mathrm{W}_{50}=132.4 * 10^{9}\left(\mathrm{C}_{\mathrm{n}}^{2}\right)^{0.65} \mu \mathrm{rad}
$$

It is noted, that the slope of the regression line is 0.65 . For the case of long exposure blur ( $b=0$ in equation (1)[3]), the atmospheric MTF can be approximated by $\operatorname{MTF}(\mathrm{f})=\exp \left\{-\left(\mathrm{f} / \mathrm{f}_{\mathrm{c}}\right)^{5 / 3}\right\}$ with the cut-off frequency $\mathrm{f}_{\mathrm{c}}=\mathrm{r}_{0} /(2.1 \lambda)$, corresponding to a total blur of $5.1 \lambda /\left(\mathrm{r}_{0} \pi \sqrt{2}\right)$ or $34 * 10^{9}\left(\mathrm{C}_{\mathrm{n}}^{2}\right)^{0.6} \mu \mathrm{rad}$, of which the slope is less steep.

Beam wander (BW) is the atmospheric effect, resulting in transverse motions of the spot in the focal plane. It may be considered as some kind of blur, especial evident when long exposure times are taken. BW is caused by irregular tilting of the incoming wave front, resulting in variations in the angle of arrival. Mainly the large eddies of the turbulence are resonsible for the wave front tilting. Fried did remove the blur from tilting in his short exposure time blur by subtracting the least-square fit of a plane to an incident wave front. Beland [9] derives BW as the root of the mean square angle of arrival, directly from the plane wave structure function, resulting in:

$$
\mathrm{BW}=\left(2.91 \mathrm{D}^{-1 / 3} \mathrm{C}_{\mathrm{n}}^{2} \mathrm{R}\right)^{0.5} \quad \text { with } \mathrm{D}=0.2 \mathrm{~m} \text { and } \mathrm{R}=15.7 * 10^{3} \mathrm{~m} \text { follows: } \mathrm{BW}=2.8^{*} 10^{8}\left(\mathrm{C}_{\mathrm{n}}^{2}\right)^{0.5} \mu \mathrm{rad}
$$

Similar to the conditions for equations (1), the turbulence spectrum is again of a Kolmogorov type, while $\mathrm{C}_{\mathrm{n}}{ }^{2}$ is taken constant along the range R. Equations (2) and (3) allow a separate analysis of both blurring effects: SE blur and BW.

\section{RETRIEVAL OF $\mathrm{C}_{\mathrm{n}}^{2}$ DATA}

From section 2 it is clear that knowledge of proper $\mathrm{C}_{\mathrm{n}}^{2}$ data is essential for blur and BW predictions. The collection of $\mathrm{C}_{\mathrm{n}}{ }^{2}$ data is however a cumbersome exercise. During FATMOSE a number of different methods were applied, described in [6] and [7]. Some of the methods are based upon the measurement of local data, such as the rapid wind speed and temperature variations in 3-dimensions with a sonic anemometer. Also the local collection of bulk data: wind speed, airand sea-temperature, relative humidity and pressure can lead to $\mathrm{C}_{\mathrm{n}}{ }^{2}$ prediction through the Monin-Obukhov similarity theory for the atmospheric boundary layer. It appeared that predictions from these data were only occasionally correct due to the previously mentioned and frequently occurring ASTD variations along the measurement path.

The Scintec BLS900 scintillometer was installed between IMT and RRL, so that its data contained some path averaging. The instrument collects scintillation data [10], which are converted into log-amplitude variations, resulting in $\mathrm{C}_{\mathrm{n}}{ }^{2}$ data by using the theory, developed by Clifford [11]. Two instruments were installed, measuring the scintillation over the same $15.7 \mathrm{~km}$ path, where the blur was measured: between IMT and the NSRI rescue station at Strandfontein. One instrument concerned the Celestron telescope with Marlin camera with the same source as used for the blur measurement; the other was a transmissometer, using a modulated source. The disadvantage was that for this long range, simple scintillation formulas, based upon the Rytov theory, are not valid due to aperture averaging at the source and at the receiver. The Rytov theory assumes point sources and receivers. When using these point apertures, saturation rapidly occurs. The use of extended apertures avoids saturation, but the relation between $\mathrm{SI}$ and $\mathrm{C}_{\mathrm{n}}{ }^{2}$ becomes more complicated, even for cases with relatively small turbulence conditions (e.g. $\mathrm{C}_{\mathrm{n}}^{2}=10^{-15}$ ).

The Rytov scintillation index for weak turbulence (normalised variance) is [8]: $\operatorname{SI}_{R}=1.23 \mathrm{C}_{n}^{2}(2 \pi / \lambda)^{7 / 6} \mathrm{R}^{11 / 6}$. For an aperture with diameter $\mathrm{D}$, the scintillation index becomes: $\mathrm{SI}_{\mathrm{D}}=\mathrm{A} * \mathrm{SI}_{R}$, where $\mathrm{A}$ is the aperture averaging factor. According to the approximation of Andrews [8], we find: $\mathrm{SI}_{\mathrm{D}}=\exp \{\mathrm{P}+\mathrm{Q}\}-1$, with:

$$
\mathrm{P}=0.49 \mathrm{SI}_{\mathrm{R}} /\left(1+0.65 \mathrm{~B}+1.11 \mathrm{SI}_{\mathrm{R}}{ }^{6 / 5}\right)^{7 / 6} \text { and } \mathrm{Q}=\left\{0.51 \mathrm{SI}_{\mathrm{R}}\left(1+0.69 \mathrm{SI}_{\mathrm{R}}{ }^{6 / 5}\right)^{-5 / 6}\right\} /\left\{1+0.9 \mathrm{~B}+0.62 \mathrm{BSI}_{\mathrm{R}}{ }^{6 / 5}\right\} ; \mathrm{B}=\left(\pi \mathrm{D}^{2}\right) /(2 \lambda \mathrm{R})
$$

It is noted, that $A$ has to be calculated for the source $\left(A_{s}\right)$ and for the receiver $\left(A_{r}\right)$, and that the product of $A_{s}$ and $A_{r}$ has to be applied for obtaining the total aperture averaging factor. For the Celestron set-up, the diameter of the receiver and the source is $0.2 \mathrm{~m}$ respectively 0.09 or $0.15 \mathrm{~m}$. For the transmissometer these values are: 0.04 and $0.2 \mathrm{~m}$. For the three combinations of apertures: $20 \times 15 \mathrm{~cm}, 20 \times 9 \mathrm{~cm}$ and $20 \times 4 \mathrm{~cm}$ the total aperture averaging factor has been calculated, 
again for $\mathrm{R}=15.7^{*} 10^{3} \mathrm{~m}$ and $\lambda=0.8^{*} 10^{-6} \mathrm{~m}$, resulting in a relation between $\log \left(\mathrm{C}_{\mathrm{n}}^{2}\right)$ and $\log \left(\mathrm{SI}_{\mathrm{D}}\right)$, as shown in Figure 4 , where $\mathrm{SI}_{\mathrm{D}}$ is the scintillation index as measured in one of the three combinations. The plots show a linear part for $\mathrm{SI}_{\mathrm{D}}$ values lower than $0.1\left(\log \left(\mathrm{SI}_{\mathrm{D}}\right)<-1\right)$ and a parabolic regression curve for $\mathrm{SI}_{\mathrm{D}}>0.1$, all with a correlation coefficient greater than 0.99. The three cases are, taking $\mathrm{U}=\log \left(\mathrm{C}_{\mathrm{n}}^{2}\right)$ and $\mathrm{V}=\log \left(\mathrm{SI}_{\mathrm{D}}\right)$ :

$15 \times 20 \mathrm{~cm} \quad \mathrm{SI}<0.1$; linear: $\mathrm{U}=1.14 * \mathrm{~V}-14.206, \quad \mathrm{SI}>0.1$; parabolic: $\mathrm{U}=2.107 * \mathrm{~V}^{2}+5.4025 * \mathrm{~V}-11.99$

$9 \times 20 \mathrm{~cm} \quad \mathrm{SI}<0.1$; linear: $\mathrm{U}=1.111 * \mathrm{~V}-14.557, \quad \mathrm{SI}>0.1$; parabolic: $\mathrm{U}=3.5205^{*} \mathrm{~V}^{2}+7.8054 * \mathrm{~V}-11.31$

$4 \times 20 \mathrm{~cm} \quad \mathrm{SI}<0.1$; linear: $\mathrm{U}=1.0485 * \mathrm{~V}-14.905, \quad \mathrm{SI}>0.1$; parabolic: $\mathrm{U}=2.8109 * \mathrm{~V}^{2}+5.2003 * \mathrm{~V}-13.356$

It is noted, that the relations (5) hold for $\mathrm{SI}_{\mathrm{D}}$ values lower than 0.5. It is clear, that the scintillation data, measured with the transmissometer and with the Celestron system allow the retrieval of lower $\mathrm{C}_{\mathrm{n}}^{2}$ data than with the BLS scintillometer. It is also shown that $\mathrm{C}_{\mathrm{n}}^{2}$ is roughly proportional to the scintillation index; for the combination of $9 \times 20 \mathrm{~cm}$ follows the

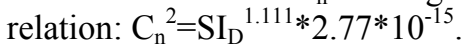

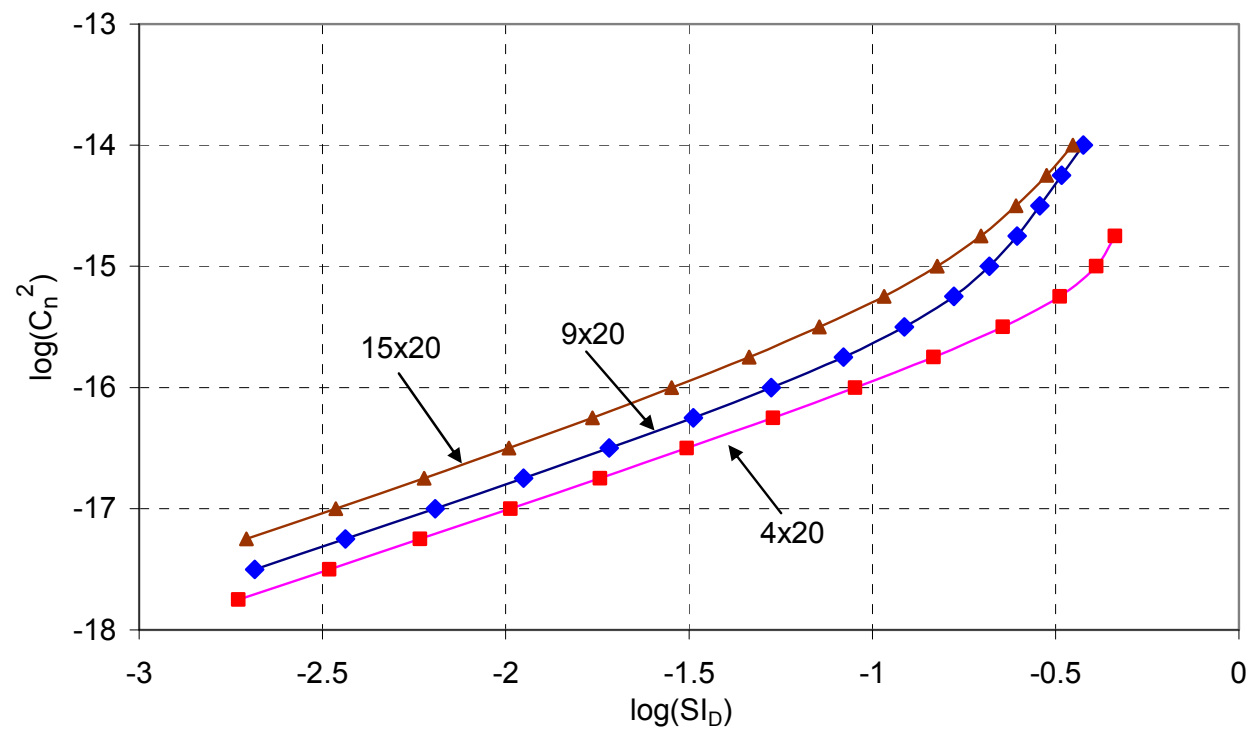

Figure 4. Relation between $\log \left(\mathrm{C}_{\mathrm{n}}{ }^{2}\right)$ and $\log \left(\mathrm{SI}_{\mathrm{D}}\right)$ including aperture averaging effect for three combinations of apertures

One remark concerns the use of an imaging system for getting SI values, because the image is containing both spot and background pixels, which have to be subtracted in some manner. Furthermore the integration time for each image is of the order of 1 millisecond, resulting in short sampling times of the turbulence. The dynamic range is limited to 10 bits. The transmissometer however with its modulated source, larger dynamic range (12 bits) and longer integration time (21 seconds) is favourable for these reasons.

\section{DATA ANALYSIS METHOD}

An image of the four sources at the previously mentioned NSRI station is shown in Figure 5. The picture on the left is taken with longer exposure time, in order to show details in the background. The picture on the right is taken with short (normal) exposure time, showing just the sources, including windows around the two central sources, as used during the image analysis. The source on the left is the modulated source, used by the transmissometer. The source on the right has a somewhat bigger aperture $(15 \mathrm{~cm})$, used for atmospheric refraction and blur studies. The two central sources, both with apertures of $9 \mathrm{~cm}$, are used for blur and differential refraction measurements. Of the two windows around a spot, the central window serves to determine the spot characteristics and the outer window area is used for getting background radiance data. The size of the central window is generally about $40 \mathrm{x} 40$ pixels (the size of one pixel is $5 \mu \mathrm{rad}$ ), while the width of the outer window strip is 10 pixels. The mean level and the standard deviation of the background pixels are determined in order to provide a threshold signal level for the pixels in the spot window. This threshold level is the mean 
background level plus three times the standard deviation. This thresholding is essential in daytime, as some parts of the background can have considerable radiance, as shown in Figure 5. For each of the image frames, the distribution of the bit levels (or spot intensities) in the spot window is read out in a special Matlab script. This script gives the intensity distribution $\mathrm{I}(\mathrm{x}, \mathrm{y})$, upon which the rest of the processing procedure is based. Here $\mathrm{x}$ and $\mathrm{y}$ are the coordinates in the focal plane. This distribution is collected for each of the 150 frames, collected within 5 seconds. These series of frames are taken every 5 minutes, which gives a total of 288 data points every day.
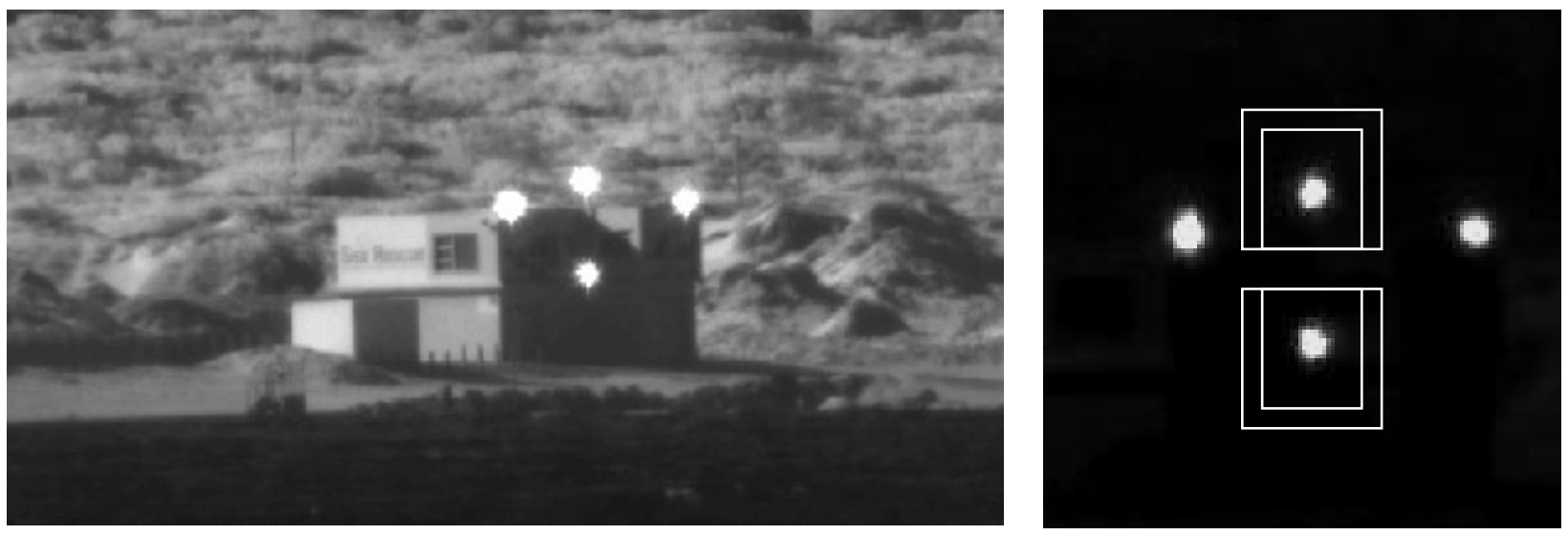

Figure 5. Image of the sources at $15.7 \mathrm{~km}$ at the NSRI station, taken with the Celestron camera system. On the right, the selection of the windows around the two centre sources is shown

At first the integrated intensity is determined: $I_{n}=\iint I_{n}(x, y) d x d y(n=1 \ldots 150)$, resulting in a mean value $I_{m}$ and a standard deviation $\mathrm{I}_{\mathrm{s}}$, from which the scintillation index SI is obtained: $\mathrm{SI}=\left(\mathrm{I}_{\mathrm{s}} / \mathrm{I}_{\mathrm{m}}\right)^{2}$. The next step is the calculation of the "centre of gravity", which coordinates $\left(\mathrm{x}_{\mathrm{cn}}, \mathrm{y}_{\mathrm{cn}}\right)$ are found from the normalised first moment of $\mathrm{I}(\mathrm{x}, \mathrm{y})$ :

$$
\mathrm{x}_{\mathrm{cn}}=\iint_{\mathrm{X}} \mathrm{I}_{\mathrm{n}}(\mathrm{x}, \mathrm{y}) \mathrm{dxdy} / \iint_{\mathrm{n}}(\mathrm{x}, \mathrm{y}) \mathrm{dxdy} \quad \mathrm{y}_{\mathrm{cn}}=\iint \mathrm{y} \mathrm{I}_{\mathrm{n}}(\mathrm{x}, \mathrm{y}) \mathrm{dxdy} / \iint \mathrm{I}_{\mathrm{n}}(\mathrm{x}, \mathrm{y}) \mathrm{dxdy}
$$

The means $\mathrm{x}_{\mathrm{cm}}$ and $\mathrm{y}_{\mathrm{cm}}$ are calculated for each series, giving the mean beam wander BW by using the equation:

$$
\mathrm{BW}=<\sqrt{ }\left\{\left(\mathrm{x}_{\mathrm{cn}}-\mathrm{x}_{\mathrm{cm}}\right)^{2}+\left(\mathrm{y}_{\mathrm{cn}}-\mathrm{y}_{\mathrm{cm}}\right)^{2}\right\}>(\mathrm{n}=1 \ldots 150)
$$

for which the relation with $\mathrm{C}_{\mathrm{n}}{ }^{2}$ is shown in equation (3). Several methods are available to express the blur size of the intensity distribution $\mathrm{I}(\mathrm{x}, \mathrm{y})$. As mentioned before, we will mainly consider the two line spread functions $\mathrm{L}(\mathrm{x})$ and $\mathrm{L}(\mathrm{y})$, due to the fact that some integration over the spot area can be taken: for $\mathrm{L}(\mathrm{x})$ in the $\mathrm{Y}$ direction and for $\mathrm{L}(\mathrm{y})$ in the $\mathrm{X}$ direction: $\mathrm{L}(\mathrm{x})=\int \mathrm{I}(\mathrm{x}, \mathrm{y})$ dy and $\mathrm{L}(\mathrm{y})=\int \mathrm{I}(\mathrm{x}, \mathrm{y}) \mathrm{dx}$. In section 2 it was found that the shape of the LSF is nearly Gaussian, in which case it is attractive to consider the normalised second moments $\mathrm{M}_{20}$ and $\mathrm{M}_{02}$ in both the $\mathrm{X}$ and $\mathrm{Y}$ direction:

$$
\mathrm{M}_{20}=\iint\left(\mathrm{x}-\mathrm{x}_{\mathrm{cn}}\right)^{2} \mathrm{I}_{\mathrm{n}}(\mathrm{x}, \mathrm{y}) \mathrm{dxdy} / \iint \mathrm{I}_{\mathrm{n}}(\mathrm{x}, \mathrm{y}) \mathrm{dxdy} \quad \mathrm{M}_{02}=\iint\left(\mathrm{y}-\mathrm{y}_{\mathrm{cn}}\right)^{2} \mathrm{I}_{\mathrm{n}}(\mathrm{x}, \mathrm{y}) \mathrm{dxdy} / \iint_{\mathrm{n}}(\mathrm{x}, \mathrm{y}) \mathrm{dxdy} \quad(\mathrm{n}=1 \ldots 150)
$$

The total blur $\sigma_{t}$ is than defined as the geometrical mean of the roots of $M_{20}$ and $M_{02}: \sigma_{t}=\sqrt{ }\left(\sqrt{ } M_{20} * \sqrt{ } M_{02}\right)$, in first instance in pixel numbers, but than converted into $\mu \mathrm{rad}$ by multiplying with a factor $5(\mu \mathrm{rad} / \mathrm{pixel})$. It is noted that the total blur is composed of the atmospheric blur $\sigma_{\mathrm{a}}$ and the sensor blur $\sigma_{\mathrm{s}}$. The atmospheric blur $\sigma_{\mathrm{a}}$ is retrieved via the relationship:

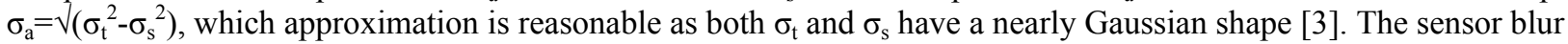
follows from the Modulation Transfer Functions (MTFs) of the Telescope $\left(\mathrm{F}_{0}\right)$, the detector $\left(\mathrm{F}_{\mathrm{c}}\right)$ and the source $\left(\mathrm{F}_{\mathrm{s}}\right)$ :

$$
\mathrm{F}_{0}=(2 / \pi)^{*}\left[\arccos \left(\mathrm{f} / \mathrm{f}_{0}\right)-\left(\mathrm{f} / \mathrm{f}_{0}\right)^{*}\left\{1-\left(\mathrm{f} / \mathrm{f}_{0}\right)^{2}\right\}^{0.5}\right] \quad \mathrm{F}_{\mathrm{c}}=\left\{\sin \left(\pi \mathrm{f} / \mathrm{f}_{\mathrm{c}}\right)\right\} /\left(\pi \mathrm{f} / \mathrm{f}_{\mathrm{c}}\right) \quad \mathrm{F}_{\mathrm{s}}=2 * \mathrm{~J}_{1}\left(\mathrm{f} / \mathrm{f}_{\mathrm{s}}\right) /\left(\mathrm{f} / \mathrm{f}_{\mathrm{s}}\right)
$$

where the telescope central obscuration is ignored, $\mathrm{f}_{0}=\mathrm{D} / \lambda=250 \mathrm{c} / \mathrm{mr}, \mathrm{f}_{\mathrm{c}}=\mathrm{f}_{\mathrm{t}} / \mathrm{d}_{\mathrm{c}}=200 \mathrm{c} / \mathrm{mr}$ and $\mathrm{f}_{\mathrm{s}}=\mathrm{R} /\left(\pi \mathrm{D}_{\mathrm{s}}\right)=55.5 \mathrm{c} / \mathrm{mr}$. Here $D$ and $f_{t}$ are the diameter and focal length of the telescope, $d_{c}$ the detector size and $D_{s}$ the diameter of the source. The product $\mathrm{F}_{0} * \mathrm{~F}_{\mathrm{c}} * \mathrm{~F}_{\mathrm{s}}$ follows roughly the Gaussian: $\mathrm{F}(\mathrm{f})=\exp \left\{-(\mathrm{f} / 78)^{2}\right\}$ for $\mathrm{D}_{\mathrm{s}}=9 \mathrm{~cm}$. A corresponding Gaussian line spread 
function can be specified for the total system: $\mathrm{L}_{\mathrm{s}}(\mathrm{x})=\exp \left\{-\left(\mathrm{x} / \sigma_{\mathrm{s}}\right)^{2} / 2\right\}$ with $\sigma_{\mathrm{s}}=1 /\left(\pi^{*} 78 \sqrt{2}\right) \mathrm{mrad}=2.89 \mu \mathrm{rad}$, to be interpreted as a measure for the sensor blur. For the source diameter of $15 \mathrm{~cm}, \sigma_{\mathrm{s}}$ is found to be: $3.63 \mu \mathrm{rad}$. It is noted, that the second moment of a normalised Gaussian distribution $\mathrm{I}(\mathrm{x})=\{1 /(\sigma \sqrt{2} \pi)\} \exp \left\{-(\mathrm{x} / \sigma)^{2} / 2\right\}$ is its variance: $\sigma^{2}$, while the fourth moment is: $3 \sigma^{4}$. Comparison of both moments provides a check of the validity of the Gaussian shape of the distribution. As shown in Figure 2, the predicted LSF exceeds the Gaussian at the outer edges. The use of $\mathrm{M}_{20}$ and $\mathrm{M}_{40}$ over estimates the blur. This is illustrated in Figure 6 for the predicted and Gaussian LSF. For this reason the widths $\mathrm{W}_{75}$, $\mathrm{W}_{50}$ and $\mathrm{W}_{25}$ were introduced in section 2 to characterize the blur. The width $\mathrm{W}_{50}$ provides after correction for the sensor blur (6.81 and $8.55 \mu \mathrm{rad}$ for the $9 \mathrm{~cm}$ resp. $15 \mathrm{~cm}$ source) the full blur width. The standard deviation $\sigma_{\mathrm{a}}, \mathrm{obtained}$ via equations (8) and (9), has to be multiplied with a factor 2.43 in order to obtain a blur size comparable with $\mathrm{W}_{50}$.

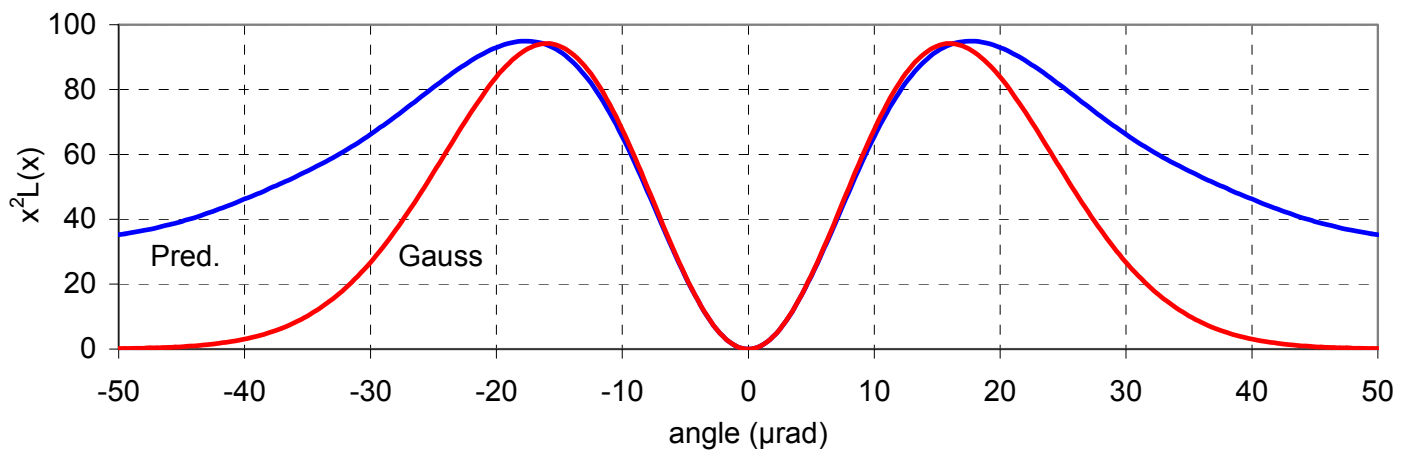

Figure 6. Comparison of the value of $x^{2} \mathrm{~L}(\mathrm{x})$ for the two LSFs in Figure 2 (right).

\section{EXAMPLES OF RAW DATA}

At first we present some raw data, showing the variation of atmospheric propagation effetcs with time. As an example, data of the Beam Wander (BW) and Scintillation Index (SI), collected by the Celestron system, are shown for the time series of 28-30 March in Figure 7. Both BW and $\log (\mathrm{SI})$ show a decreasing trend, together with considerable noise.

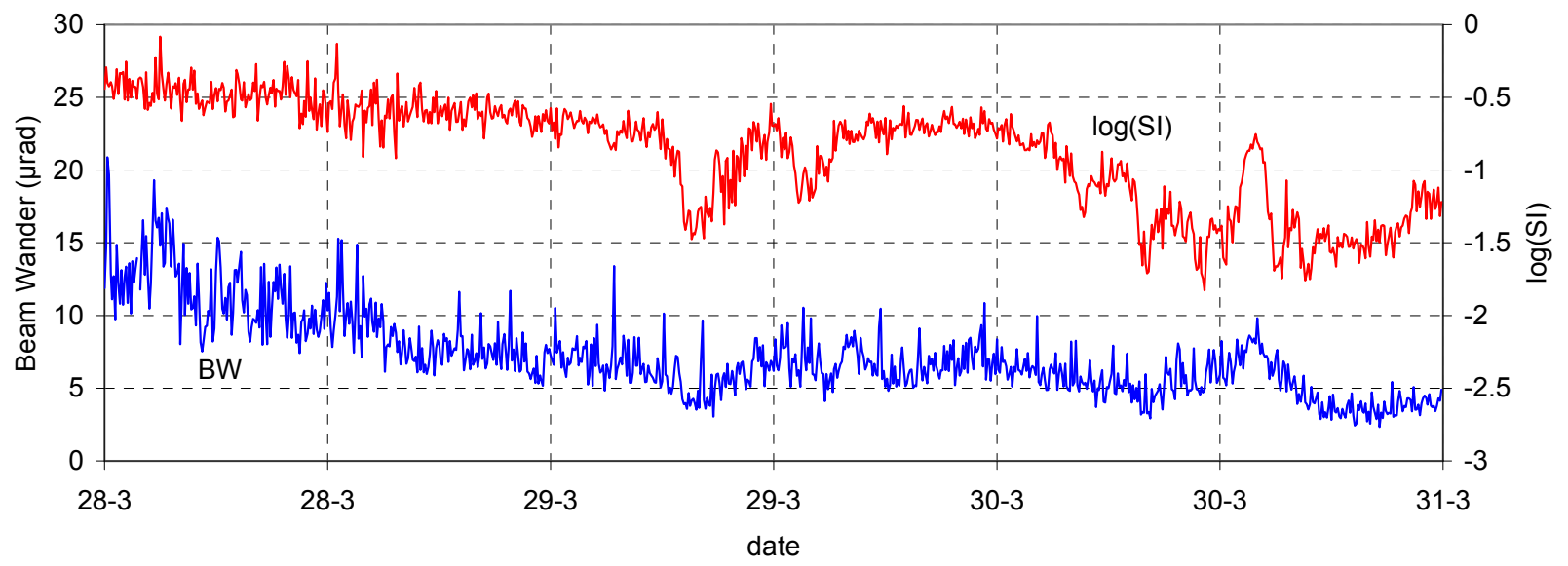

Figure 7. Example of a time series of the Beam Wander and $\log (\mathrm{SI})$ data for the period: $28-30$ March 2010

Each data point gives a mean value of 150 samples ( 5 seconds of data). The individual samples show even greater fluctuations, which corresponds to the large fluctuations found in the data from the BLS scintillometer. For the same period as in Figure $7, \mathrm{C}_{\mathrm{n}}^{2}$ data, collected by the BLS system, are compared with the $\mathrm{C}_{\mathrm{n}}{ }^{2}$ data, obtained via the conversion equations (5), collected by the MSRT transmissometer and the Celestron. The cloud of data points in the $\mathrm{C}_{\mathrm{n}}{ }^{2}$ plot for BLS and Celestron data (for the same period as in Figure 7), shown in Figure 8, indicates that the correlation is rather poor, caused by the variations in the weather conditions, that are likely to occur over longer periods of time. 
Especially in cases with changing air temperature and wind direction, the conditions along the path may vary, resulting in different turbulence effects for the BLS and Celestron system. It is further noticed, that within one hour with stable atmospheric conditions, $\mathrm{C}_{\mathrm{n}}^{2}$ values (measured each two minutes) may easily vary a factor 2 around the mean value. In the central plot of Figure 8, the retrieved $\mathrm{C}_{\mathrm{n}}{ }^{2}$ data from the Celestron camera and the MSRT transmissometer are compared, showing a reasonable correlation over several decades. Next, in the right plot, the BW data, measured in the same period are compared with BW predictions from equation (3), based upon the $\mathrm{C}_{\mathrm{n}}^{2}$ data after retrieval from the Celestron SI data. The correlation is good, although the predictions are systematically too high for large BW values.
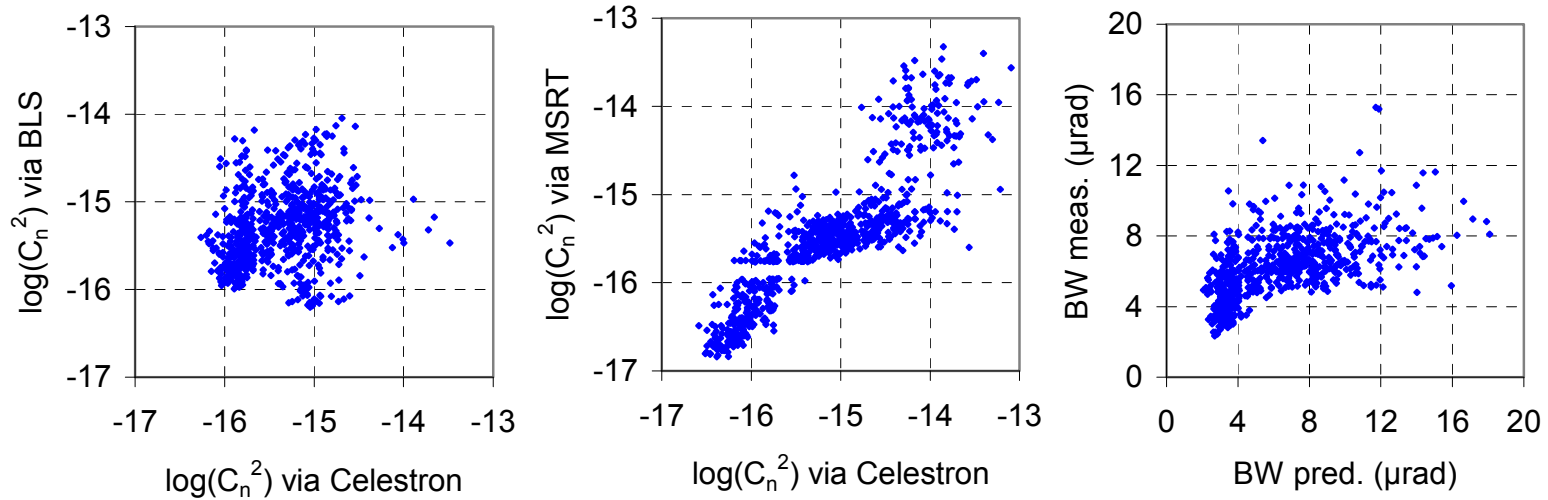

Figure 8. Plots of $\mathrm{C}_{\mathrm{n}}^{2}$, measured by the BLS system and retrieved via the SI data from the Celestron camera and the MSRT transmissometer (left and centre). On the right measured and predicted BW are compared

The data, taken over several days, include large scale turbulence effects, showing moving air masses with potentially different $\mathrm{C}_{\mathrm{n}}^{2}$ values and bringing low frequency effects, as was shown in the scintillation spectra [7]. By zooming in to a smaller time scale, a series of 150 frames (5 seconds), it is found that strong fluctuations remain, as well in the second moments $\mathrm{M}_{20}$ and $\mathrm{M}_{02}$, as in the Beam Wander and spot width $\mathrm{W}_{50}$, as is shown in Figure 9. These data are taken on the $29^{\text {th }}$ of March at 06.30 . The mean value and standard deviation of $\mathrm{W}_{50}$ (blur) is 27.4 resp. $5.1 \mu \mathrm{rad}$ and for the BW: 3.89 resp. $2.24 \mu \mathrm{rad}$. The value of $\mathrm{C}_{\mathrm{n}}{ }^{2}$ was $1.2 * 10^{-15} \mathrm{~m}^{-2 / 3}$ at this time.
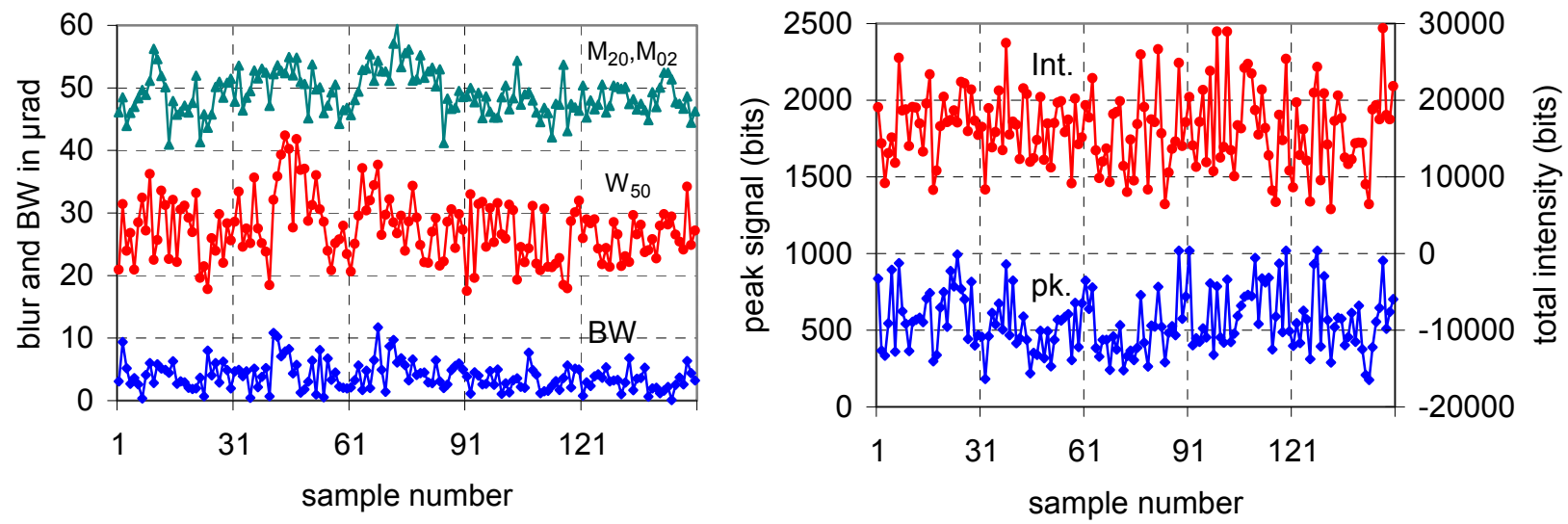

Figure 9. Examples of Celestron data for the 150 frame series of 29 March 06.30. Left: blur via $\mathrm{W}_{50}$ and the second moments $\mathrm{M}_{20}$ and $\mathrm{M}_{02}\left(\sqrt{ }\left(\mathrm{M}_{20} * \mathrm{M}_{02}\right)\right)$ and Beam Wander (BW). Right: the peak signal and the total intensity

The peak signal and the integrated intensity $\mathrm{I}_{\mathrm{n}}$ are also shown in Figure 9; the ratio of the standard deviation and the mean value is in both cases 0.36 resp. 0.31. It is found, that this ratio is smaller for $\mathrm{W}_{50}(0.19)$, due to the integration when taking the LSFs. In a further analysis of the same series, the second and the fourth moment have been compared, the ratio of which should be $\sigma^{2} / 3 \sigma^{4}$ for a true Gaussian LSF. A plot of all 150 data points for $\sqrt{ } \mathrm{M}_{04} / 3$ versus $\mathrm{M}_{02}$ should follow a straight line, which is not occurring in this example, as shown in Figure 10 (left). It may be concluded that the LSF is non-Gaussian, as is mostly the case and is also predicted by the theory (see Figure 2). 
The central plot in Figure 10 concerns the effect of the peak signal level on the blur value $\left(\mathrm{W}_{50}\right)$, where (as before) for $\mathrm{W}_{50}$ the geometrical mean of the horizontal and vertical values of $\mathrm{W}_{50}$ is taken: $\mathrm{W}_{50}=\left(\mathrm{W}_{50 \mathrm{H}} * \mathrm{~W}_{50 \mathrm{~V}}\right)^{0.5}$. It is shown that there is a minor decrease in $\mathrm{W}_{50}$ value with increasing peak height. This result makes this method of blur determination stronger. In the plot on the right in Figure 10 the variances in horizontal and vertical direction are compared. The plot shows that both parameters vary more or less in the same way and that the variance in the vertical direction is somwhat larger. This effect occurs systematically in most of the atmospheric situations and can be explained by the presence of larger gradients in the vertical temperature profile in the marine boundary layer [6].
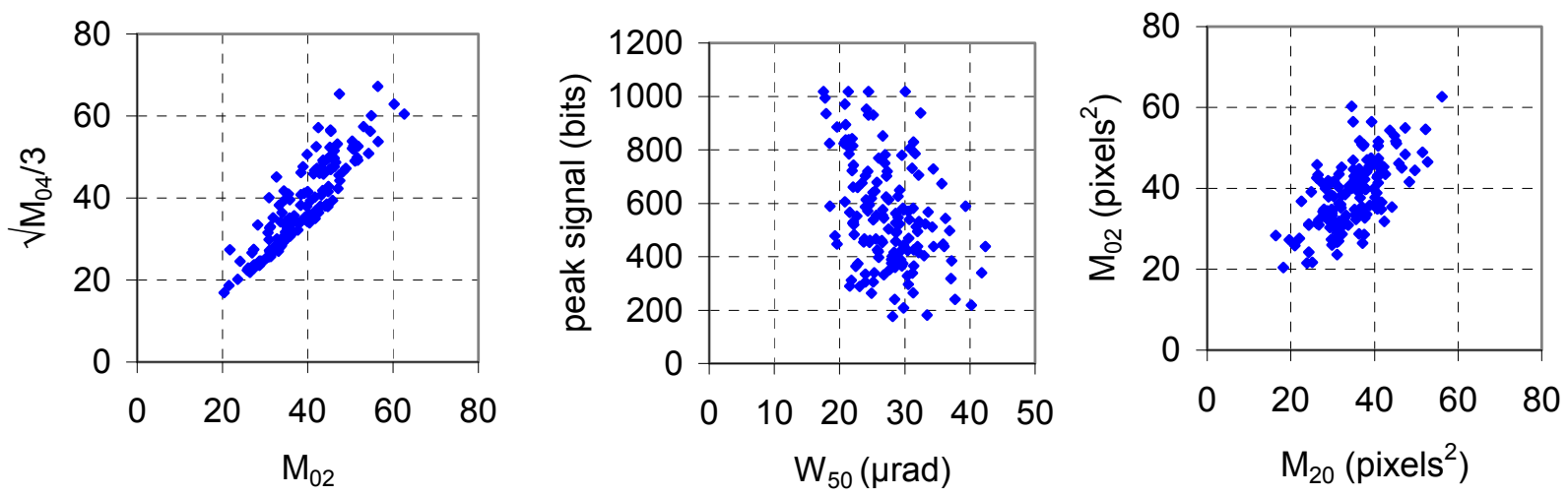

Figure 10. Left: comparison of the second and fourth moment for the data of Figure 9. Centre: blur $\left(\mathrm{W}_{50}\right)$ versus the peak signal. Right: comparison of the horizontal $\left(\mathrm{M}_{20}\right)$ and vertical $\left(\mathrm{M}_{02}\right)$ second moments

A closer look at the Line Spread Functions (LSFs), basically used for determining $\mathrm{W}_{50}$, is shown in Figure 11. It appears that for small and moderate blur conditions, the signal has a rather strong peak, contrary to the theoretical prediction as shown in Figure 2. This peaks probably arise due to coherence effects in a significant area (related to the transverse coherence length $\rho_{0}$, which is roughly $2 \mathrm{~cm}$ ) within the entrance pupil of the Celestron, resulting in strong interference. The three examples concern small, medium and large blur conditions within the same series of 150 frames.
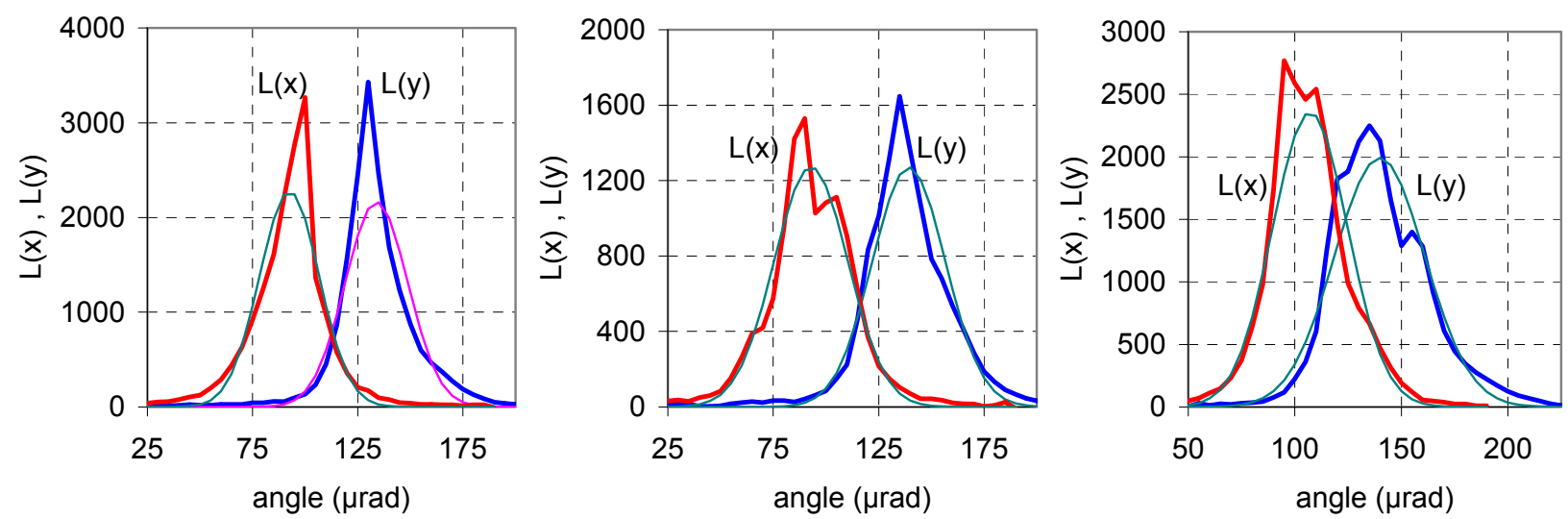

Figure 11. Examples of three horizontal $\{\mathrm{L}(\mathrm{x})\}$ and vertical $\{\mathrm{L}(\mathrm{y})\} \mathrm{LSFs}$ from the data of Figure 9 (including Gauss fits) for small (19.0 $\mu \mathrm{rad}$, left), medium (32.0 $\mu \mathrm{rad}$, centre) and large (36.5 $\mu \mathrm{rad}$, right) blur conditions; 29 March 2010-06.30

The plots also show the Gaussian fits to each of the LSFs. It was found, that the larger the blur, the better the fit of the Gaussian curves. In some cases, one blur spot contained two separate peaks, indicating that two areas of coherence were present in the entrance pupil. It is noted, that with a mean blur size of $27.4 \mu \mathrm{rad}$, several spots of the 150 frames have a blur size of less than $20 \mu \mathrm{rad}$. A trained observer, looking at this kind of imagery, is capable to filter the sharpest images, as will do a modern processing algorithm. Taking as blur size the mean value, one may be sure that in operational conditions, appropriate point target discrimination can be accomplished if the number of blur sizes per target is adequate. 


\section{COMPARISON OF MEASUREMENTS AND PREDICTIONS}

For a more in-depth comparison of predicted and measured blur characteristics, a selection of data point across the FATMOSE trials period has been made, similar to the 475 events as described in [3]. In this case we have taken 107 events with a representative variety of atmospheric conditions, although the weather conditions were roughly constant a few hours around the time of the events. Minimum blur values of about $14 \mu \mathrm{rad}$ were found, while the maximum values of more than $100 \mu \mathrm{rad}$ were collected in March 2010, when $\mathrm{C}_{\mathrm{n}}{ }^{2}$ was rising considerably above $10^{-14}$. Plots of the most important parameters for the selected events are presented in Figures 12 and 13.

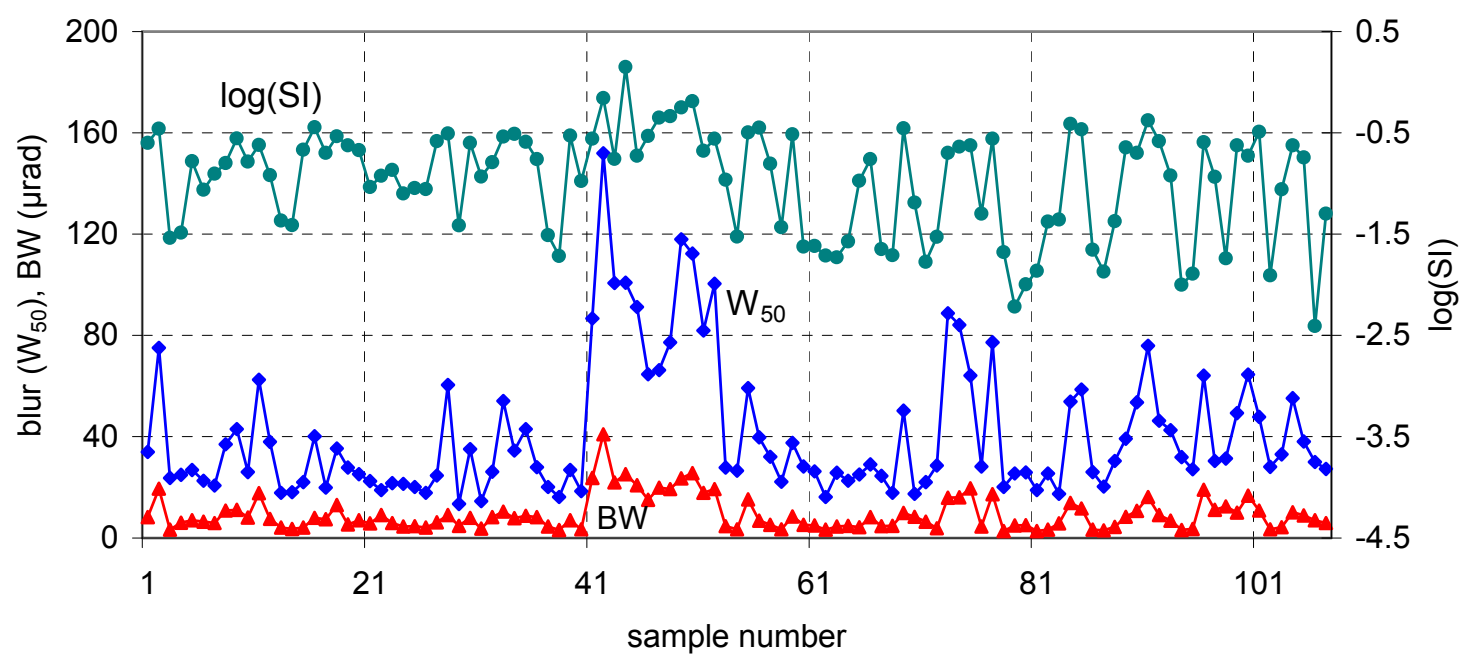

Figure 12. Blur $\left(\mathrm{W}_{50}\right)$, BW and $\log (\mathrm{SI})$ for the selected events during the FATMOSE campaign

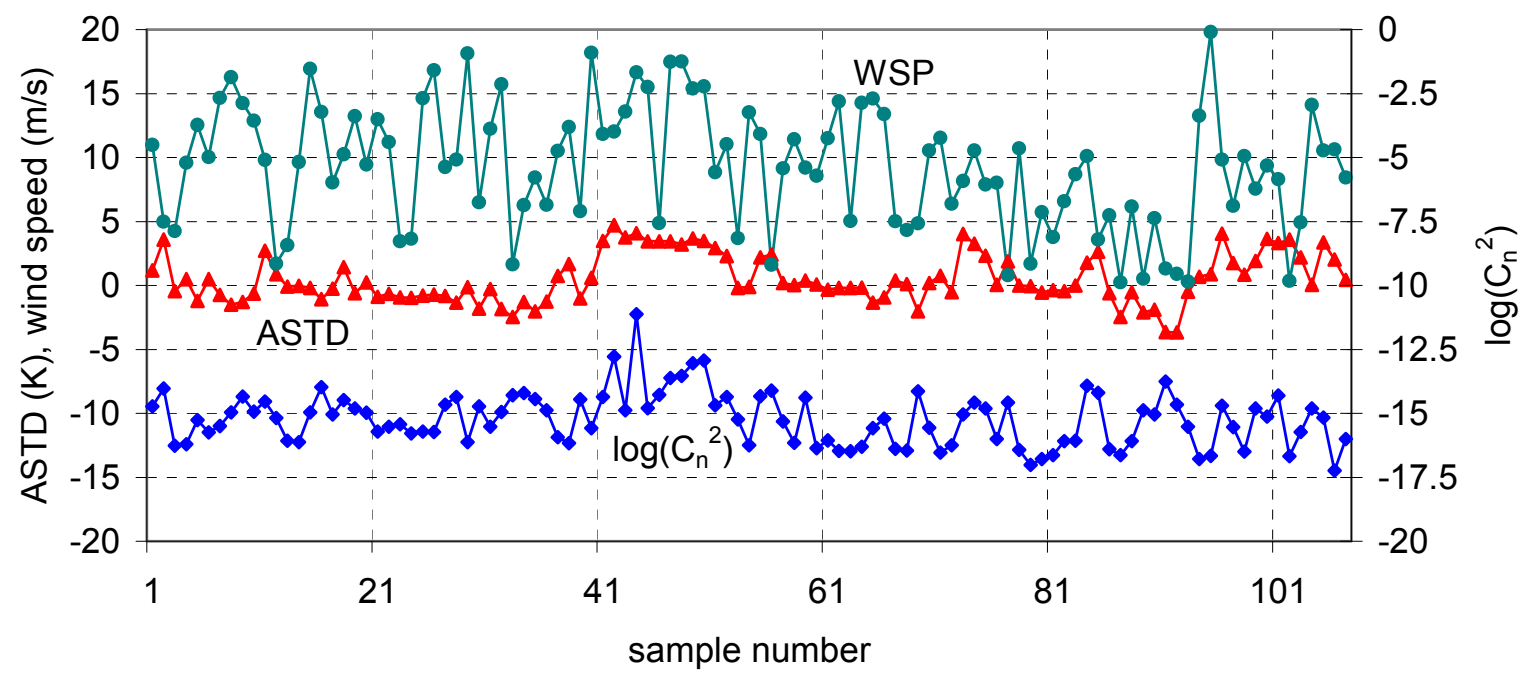

Figure 13. Wind speed, ASTD and $\log \left(\mathrm{C}_{\mathrm{n}}^{2}\right)$, retrieved from the Celestron SI, for the selected events

It is shown, that the largest blur occurs when the ASTD is more than $3 \mathrm{~K}$ and high wind speed. Small blur may occur however as well at low as at high wind speed. The blur and BW data correlate linearly rather good, as should be the case. According to the equations (2) and (3), $\mathrm{W}_{50}$ and BW are proportional to respectively $\left.\left(\mathrm{C}_{\mathrm{n}}\right)^{2}\right)^{0.65}$ and $\left(\mathrm{C}_{\mathrm{n}}{ }^{2}\right)^{0.5}$, providing the direct relation: $\mathrm{BW}=0.76 * \mathrm{~W}_{50} 0.77$. For $\mathrm{W}_{50}=40 \mu \mathrm{rad}$, the $\mathrm{BW}$ should be $13 \mu \mathrm{rad}$. The linear regression line, corresponding to the Figure 12 data: $\mathrm{BW}=0.234 * \mathrm{~W}_{50}-0.29 \mu \mathrm{rad}\left(\mathrm{R}^{2}=0.88\right)$ gives a measured $\mathrm{BW}$ of about $9 \mu \mathrm{rad}$, which indicates, that the measured $\mathrm{BW}$ is smaller than the predicted one. The difference is anyway not dramatically poor. 
In Figure 14 (left), a comparison is presented between the blur, measured with the $\mathrm{W}_{50}$ method and via the variances $\mathrm{M}_{20}$ and $\mathrm{M}_{02}$. As expected, for large blur conditions, the results are about the same, because of the nearly Gaussian shape of the LSFs. For small blur, the "peak" effect in the signal dominates, proving that the $\mathrm{W}_{50}$ method of blur determination is superior. The central plot in Figure 14 shows a comparison between the measured blur (again for the same selected data series in Figures 12 and 13) and the blur, predicted with equation (2), both via $\mathrm{W}_{50}$, while the $\mathrm{C}_{\mathrm{n}}{ }^{2}$ data are taken from the BLS system. It is found that the measured and predicted blur correlate linearly rather good following the regression line: $\mathrm{y}=1.33 \mathrm{x}-18.4 \mu \mathrm{rad}\left(\mathrm{R}^{2}=0.79\right)$. Apparently the measured blur does not reach mean $\mathrm{W}_{50}$ values lower than $16 \mu \mathrm{rad}$, but it is reminded, that several blur values as low as $10 \mu \mathrm{rad}$ were found in the series of 150 frames.
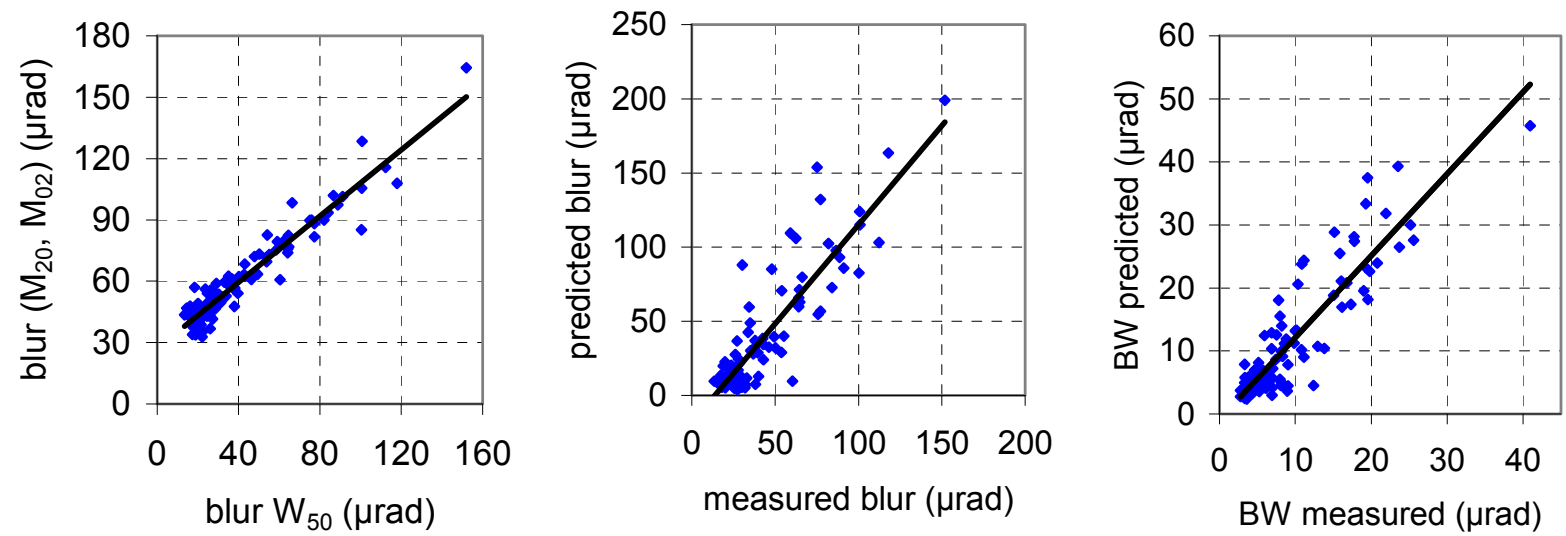

Figure 14. Relations between blur, measured via $\mathrm{W}_{50}$ and via the second moments (left), measured and predicted blur (via $\mathrm{W}_{50}$ method) (centre) and measured and predicted Beam Wander (right); same data series as in Figure 12 and 13

In the plot on the right in Figure 14, a similar comparison is given for the Beam Wander, where equation (3) is used for the prediction (taking the $\mathrm{C}_{\mathrm{n}}^{2}$ data from the BLS). Similar to Figure 8, the predicted BW is somewhat higher than the measured one, illustrated by the regression line: $y=1.30 x-0.88 \mu \mathrm{rad}\left(\mathrm{R}^{2}=0.81\right)$. The spread in the data points in Figure 14 is moderate and follows the spread in the measured data $\left(\mathrm{C}_{\mathrm{n}}^{2}\right.$, blur and $\left.\mathrm{BW}\right)$. The regression lines can be used to predict "real" blur and $\mathrm{BW}$ data for any value of $\mathrm{C}_{\mathrm{n}}^{2}$ and range.

\section{DISCUSSION AND CONCLUSIONS}

Departing from the theory on imaging performance through a turbulent atmosphere, developed by Fried, the atmospheric MTF has been converted into an LSF, allowing the use of an alternative parameter for atmospheric blur: $\mathrm{W}_{50}$. With this blur, defined as the width of the LSF at $50 \%$ of the peak height, two point targets, separated by this distance, can just be discriminated by an observer. $\mathrm{W}_{50}$ has been derived from the "Fried" theory with the advantage that more attention is spent on the high frequency part of the MTF. The blur, discussed here, concerns the short term blur, where the spot dancing (Beam Wander) is removed from the long exposure blur. For several series of images, $\mathrm{W}_{50}$ has been measured and compared to the formerly used method of spot analysis, based upon the second moments. It was shown that this latter method provides more blur due to the effect of the "shoulders" of the LSF. In reality, many of the LSFs show a more or less "spiky"nature, at least in most of the images with moderate or less blur within a series.

Attention is spent on the short and long term uncertainties in $\mathrm{C}_{\mathrm{n}}{ }^{2}$ values, which lead to uncertainties in blur prediction and are inherent to the nature of turbulence, involving small and large scale eddies with different frequency scales. In addition the $\mathrm{C}_{\mathrm{n}}{ }^{2}$ value may vary along the path, which appears also from the comparison of the data collected with a local instrument (BLS) and $\mathrm{C}_{\mathrm{n}}^{2}$, retrieved from the scintillation index, measured along the total path. For a selected set of blur measurements, taken at more or less stable conditions, the measured blur is compared with the predicted blur. It is found, that prediction and measurement correspond perfect for blur values of about $50 \mu \mathrm{rad}$. For smaller blur, the prediction is too low and for larger blur the prediction is somewhat too high. It is clear however, that the new method of analysis, described in this paper, provides a better agreement between theory and measurement. The Beam Wander data show that the predicted $\mathrm{BW}$ is about $1.3 \mathrm{x}$ bigger than the measured one. 
Although Beam Wander can seriously reduce the image quality for a human observer, it is assumed, that modern image processing algorithms are capable to limit this reduction. The most important atmospheric performance reduction effect is therefore considered to be the short term blur with exposure times of $1 \mathrm{~ms}$ or less. An illustration of the way, how the parameters, described in this paper, can be used to determine the range performance, is shown in Figure 15 . When $\mathrm{C}_{\mathrm{n}}{ }^{2}$ is given, $\mathrm{W}_{50}$ can be predicted by using equation (2), which becomes for any range $\mathrm{R}: \mathrm{W}_{50}=132.4^{*} 10^{9}\left(\mathrm{C}_{\mathrm{n}}^{2}\right)^{0.65}(\mathrm{R} / 15.7)^{0.6}$ to be converted into a real blur by the inverted trendline of Figure 14 (centre): real blur=(predicted blur +18.4$) / 1.33 \mu \mathrm{rad}$. The total blur is obtained by adding quadratically the sensor blur (Celestron $+9 \mathrm{~cm}$ source): $6.81 \mu \mathrm{rad}$. This total blur is shown as function of range for two values of $\mathrm{C}_{\mathrm{n}}^{2}$. Along the vertical axis is also given the $1 / 6$ of the size of the object to be classified. For the atmospheric contrast loss, an extinction coefficient of $0.05 \mathrm{~km}^{-1}$ is taken. Range performances $\mathrm{R}_{1}$ and $\mathrm{R}_{2}$ for the sensor under investigation are found to be: 15 and $19.5 \mathrm{~km}$ for $\mathrm{C}_{\mathrm{n}}^{2}$ values of $10^{-15}$ resp. $10^{-16} \mathrm{~m}^{-2 / 3}$.

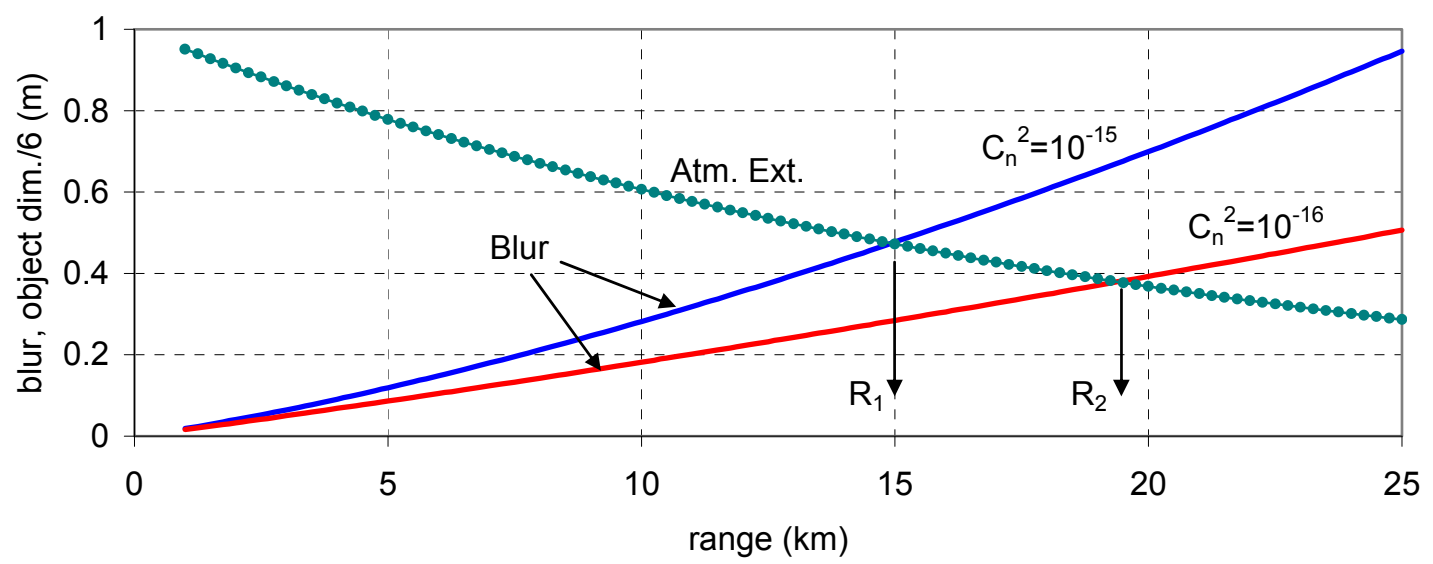

Figure 15. Illustration of graphical determination of range performance in a practical case for two $\mathrm{C}_{\mathrm{n}}^{2}$ values

We thank Peter Fritz, Leo Cohen and Rob Kemp of TNO and all involved personnel from IMT for their support in the preparation of the equipment and also for the execution of the FATMOSE trial, data storage and analysis.

\section{REFERENCES}

[1] David L. Fried, Optical resolution through a randomly inhomogeneous medium, JOSA, 56, 1372-1379 (1966)

[2] Gerald C. Holst, Electro-Optical Imaging System Performance ( ${ }^{\text {rd }}$ ed.), SPIE Press Monograph PM 121, 2003

[3] Arie N. de Jong et al, Long-term measurements of atmospheric point spread functions over littoral waters, as determined by atmospheric turbulence, SPIE Volume 8355, Infrared Imaging Systems: Design, Analysis, Modeling and Testing XXIII, Baltimore, April 2012

[4] Arie N. de Jong et al, Application of year-round atmospheric transmission data, collected with the MSRT multiband transmissometer during the FATMOSE trial in the False Bay area, SPIE Volume 8161, Atmospheric Optics: Turbulence and Propagation, San Diego, August 2011

[5] Arie N. de Jong et al, Validation of atmospheric propagation models in littoral waters, Optical Engineering 52(4) (April 2013)

[6] Arie N. de Jong et al, Marine boundary layer investigations in the False Bay, supported by optical refraction and scintillation measurements, SPIE Volume 8178, Optics in Atmospheric Propagation and Adaptive Systems XIV, Prague, September 2011

[7] Arie N. de Jong et al, Characteristics of long-range scintillation data over maritime coastal areas, SPIE Volume 8535, Optics in Atmospheric Propagation and Adaptive Systems XV, Edinburgh, September 2012

[8] Larry C. Andrews and Ronald L. Philips, Laser Beam Propagation through Random Media, $2^{\text {nd }}$ ed., SPIE Press, Bellingham USA, 2005

[9] Robert R. Beland, Propagation through Atmospheric Optical Turbulence, The Infrared \& Electro-Optical Systems Handbook, Volume 2, SPIE Optical Engineering Press, 1993

[10] Scintec AG, Scintec Boundary Layer Scintillometer Manual (revision 1.44), Tuebingen, November 2007

[11] S.F. Clifford et al, Saturation of optical scintillation by strong turbulence, JOSA Vol. 64, No. 2, February 1974 